\title{
Evidence on the economic value of end-of- life and palliative care interventions: a narrative review of reviews
}

\author{
Xhyljeta Luta ${ }^{1,2^{*}} \mathbb{D}$, Baptiste Ottino ${ }^{1}$, Peter Hall ${ }^{3}$, Joanna Bowden ${ }^{3,4,5}$, Bee Wee ${ }^{6}$, Joanne Droney ${ }^{2,7}$, Julia Riley ${ }^{2,7}$ and
} Joachim Marti ${ }^{1,2}$

\begin{abstract}
Background: As the demand for palliative care increases, more information is needed on how efficient different types of palliative care models are for providing care to dying patients and their caregivers. Evidence on the economic value of treatments and interventions is key to informing resource allocation and ultimately improving the quality and efficiency of healthcare delivery. We assessed the available evidence on the economic value of palliative and end-of-life care interventions across various settings.
\end{abstract}

Methods: Reviews published between 2000 and 2019 were included. We included reviews that focused on costeffectiveness, intervention costs and/or healthcare resource use. Two reviewers extracted data independently and in duplicate from the included studies. Data on the key characteristics of the studies were extracted, including the aim of the study, design, population, type of intervention and comparator, (cost-) effectiveness resource use, main findings and conclusions.

Results: A total of 43 reviews were included in the analysis. Overall, most evidence on cost-effectiveness relates to home-based interventions and suggests that they offer substantial savings to the health system, including a decrease in total healthcare costs, resource use and improvement in patient and caregivers' outcomes. The evidence of interventions delivered across other settings was generally inconsistent.

Conclusions: Some palliative care models may contribute to dual improvement in quality of care via lower rates of aggressive medicalization in the last phase of life accompanied by a reduction in costs. Hospital-based palliative care interventions may improve patient outcomes, healthcare utilization and costs. There is a need for greater consistency in reporting outcome measures, the informal costs of caring, and costs associated with hospice.

Keywords: End-of-life care, Terminal care, Palliative care, Cost - effectiveness, Health care costs

\section{Background}

In the context of increasing pressures on health budgets, evidence on the economic value of treatments and interventions is key to informing resource allocation and

\footnotetext{
* Correspondence: xhyljeta.luta@gmail.com

${ }^{1}$ Centre for Primary Care and Public Health (Unisanté), University of Lausanne, Route de la Corniche 10, CH-1010 Lausanne, Switzerland ${ }^{2}$ Institute of Global Health Innovation, Department of Surgery and Cancer, Imperial College London, London, UK

Full list of author information is available at the end of the article
}

improving the quality and efficiency of healthcare delivery. As an important share of healthcare expenditures occurs in the last months of life [1-3], a good understanding of the costs and benefits of care delivered during this period is particularly important. Whether dying patients are receiving "appropriate" care has been the focus of recent debates $[4,5]$. Notably, there are concerns that many patients are admitted to the hospital and undergo invasive procedures at the end-of-life

(C) The Author(s). 2021 Open Access This article is licensed under a Creative Commons Attribution 4.0 International License, which permits use, sharing, adaptation, distribution and reproduction in any medium or format, as long as you give appropriate credit to the original author(s) and the source, provide a link to the Creative Commons licence, and indicate if changes were made. The images or other third party material in this article are included in the article's Creative Commons licence, unless indicated otherwise in a credit line to the material. If material is not included in the article's Creative Commons licence and your intended use is not permitted by statutory regulation or exceeds the permitted use, you will need to obtain permission directly from the copyright holder. To view a copy of this licence, visit http://creativecommons.org/licenses/by/4.0/. The Creative Commons Public Domain Dedication waiver (http://creativecommons.org/publicdomain/zero/1.0/) applies to the data made available in this article, unless otherwise stated in a credit line to the data. 
without evidence of clinical benefits and improved quality of life (QoL); more than $80 \%$ of decedents are hospitalized at least once in the last 180 days of life in several countries [6]. In addition, research shows that such treatments are often counter to patient and/or caregiver preferences $[7,8]$. Palliative and end-of-life care services and interventions have the potential to improve the quality, appropriateness and efficiency of care provided at the end-of-life from both the perspective of patients and their families and the health system as a whole [9]. Palliative care has been associated with improved patient outcomes, such as pain and symptom management [10], improved communication [11], higher satisfaction with care [12], improved QoL [13], reduced healthcare costs $[14,15]$ and an increased likelihood of dying in one's preferred place [16]. Additionally, evidence suggests that such models of care could reduce healthcare resource use, including emergency hospital admissions, length of hospital stays (LOS) and ICU admissions [17-19].

As the demand for palliative care services increases, more information is needed on how effective and efficient different types of palliative care models are for providing care to patients and their caregivers. In particular, high-quality economic evidence regarding end-of-life and palliative care interventions is crucial to adequately support and develop new models of care that have the potential to improve the experience of patients and their relatives, avoid unnecessary treatments, and potentially reduce healthcare costs. Prior research has shown that the quality of economic evidence in the area is mixed [20]; it is often limited to assessments of reduced healthcare utilization, without proper measurement of intervention costs and/or valuation of benefits [21]. While several reviews on the topic of palliative care have been published in recent years, few have assessed the effectiveness and cost-effectiveness of palliative care interventions. Existing reviews have mainly focused on particular populations (e.g., cancer) [22], specific interventions (e.g., advance care planning, ACP) [23], or settings (e.g., home-setting) [24]. A recent review of international evidence provided important insights into a wide range of palliative care models. It found that irrespective of setting or patient characteristics, palliative care seem to be beneficial to the patients and may reduce total healthcare costs [25]. However, a more detailed assessment of effectiveness and cost-effectiveness has not been identified.

The aim of this systematic review is to provide a comprehensive overview of the available evidence published between 2000 and 2019 on the economic value of palliative and end-of-life care interventions across various settings (i.e., community, home, hospital, etc.). Due to growing evidence from multiple systematic reviews, a review of reviews is considered the most appropriate approach for bringing together the available evidence together on different interventions [26, 27].

We focused our search on published reviews that contained at least some economic evidence, including measures of cost-effectiveness, intervention costs and/or impact on healthcare use. Such knowledge might be valuable to support health policy makers in making resource allocation decisions and commissioning palliative care services.

\section{Methods}

This systematic review was performed according to PRIS MA guidelines (Preferred Reporting Items for Systematic Reviews and Meta-Analyses) [28]. This review is guided by Smith et al [26] methodology for conducting systematic reviews of systematic reviews. This review is registered in PROSPERO (registration number: CRD42018110910).

\section{Search strategies}

We performed systematic searches using Ovid in the following databases: Medline, Embase, PubMed, Cinahl, Psychinfo, Scisearch and Cochrane. We searched reviews published between January 2000 and September 24, 2019, using both MESH and keywords in the fields of palliative and end-of-life care and health economics (Table 1). Reference lists of included reviews were screened for relevant studies. We also performed Google Scholar searches using key search terms ('systematic review', 'palliative care', 'cost-effectiveness').

\section{Study selection}

We included systematic reviews focusing on quantitative assessments of intervention effectiveness that contained economic evidence on cost-effectiveness, intervention costs and/or resource use. We included interventions

Table 1 Search Strategy

Ovid MEDLINE(R) Epub Ahead of Print, In-Process \& Other NonIndexed Citations, Ovid MEDLINE(R) Daily and Ovid MEDLINE(R) < 1946 to Present>

\# Search Strategy

1 exp Terminal Care/ or exp. Palliative Care/ or exp. Terminally III/ or ((End adj2 life adj2 care) or EoL care or (terminal* adj2 (care or caring or ill* or disease*)) or palliat* or dying or (Advanced adj3 (disease* or illness*)) or end stage*).ti,ab,kf.

2 (cost: or cost benefit analys: or health care costs).mp.

3 ((exp Review Literature as Topic/ or exp. Review/ or (literature adj3 review*).ab,ti.) and ((medline or medlars or embase or pubmed or cinahl or amed or psychlit or psyclit or psychinfo or psycinfo or scisearch or cochrane).ab,ti. or Retracted Publication.pt.)) or MetaAnalysis as Topic/ or Meta-analysis.pt. or (systematic* adj2 (review* or overview)).ab,ti. or ((meta adj1 anal*) or metaanal* or metanal*).ab,ti.

41 and 2 and 3

5 limit 4 to (english language and $y r=$ "2000 -Current") 
related to palliative and end-of-life care without restriction of the setting or comparator definition. Following Brereton et al. (2017) [25], palliative and end-of-life care models/interventions were defined as "any structured care model involving multiple components, including who delivers (e.g., professionals, caregivers) the intervention (specialist or generalist palliative care), where (e.g., hospital), to whom (care recipients), when (i.e., timing and duration), how (e.g., face to face) and for what purpose (i.e., expected outcomes)." Details on inclusion and exclusion criteria are reported in Table 2.

\section{Study selection}

Two reviewers (BO, XL) screened independently and in duplicate all titles and abstracts using the inclusion and exclusion criteria (Table 1). A third reviewer (JM) provided arbitration in the event of disagreement. The same reviewers assessed the full texts of potentially relevant for eligibility. Any disagreement was resolved by discussion and by consulting the third reviewer.

\section{Assessment of quality of included studies}

We assessed the methodological quality of included studies using the AMSTAR. We assessed the methodological quality of included studies using the AMSTAR 2 (A Measurement Tool to Assess Reviews) which is a critical appraisal tool for systematic reviews that include randomized or non-randomised studies of healthcare interventions, or both [29]. The reviews were rated as low, medium quality or high quality.

\section{Data extraction}

Two authors (XL, BO) extracted data using a predefined extraction form, and any discrepancies were resolved by a third reviewer. Data on the key characteristics of the studies were extracted, including information about the aim of the review, design, population, type of intervention and comparator, information on (cost) effectiveness and resource use, and main findings and conclusions.

\section{Data synthesis and analysis}

The reviews were too heterogeneous in terms of disease, setting and outcomes measured to perform a metaanalysis; a narrative synthesis was considered more appropriate. We organized the evidence according to the main outcomes reported, i.e.: (1) cost-effectiveness, (2) costs, and (3) resource use. In each section, we discuss evidence by intervention setting and/or type.

\section{Results}

The initial searches identified 435reviews. Finally, 43 review articles were included in the analysis. Figure 1 provides details on searches and study selection. Over half of the reviews (Table 3) were published between 2011 and 2018 and included predominantly cancer patients. A wide range of palliative and end-of-life care models were described and comparator models were often described as usual care, which varied across studies, or was not specified. Most of the reviews $(n=21)$ involved interventions delivered in multiple settings [20-23, 25, 30-50]. Nine reviews examined interventions in the hospital setting [20, 50-58]. Of these, 3 focused on ICU [51-53], and 1 on surgical patients [57]. Three reviews involved

Table 2 Inclusion and exclusion criteria

\begin{tabular}{|c|c|c|}
\hline Criteria & Inclusion & Exclusion \\
\hline Type of study & $\begin{array}{l}\text { Review-level (review of reviews) evidence focusing on } \\
\text { quantitative assessment effectiveness in palliative care } \\
\text { interventions. } \\
\text { Reviews of all types of original studies; reviews of reviews. }\end{array}$ & $\begin{array}{l}\text { Not review-level evidence (primary studies). } \\
\text { Opinion papers, editorials, conference abstracts. } \\
\text { Reviews of qualitative studies. }\end{array}$ \\
\hline Dates & 2000-2019 & Outside the date range 2000-2018 \\
\hline Population & $\begin{array}{l}\text { Reviews considering terminally ill adults ( } 18 \text { years old and } \\
\text { over) and considering patients with varying illnesses. }\end{array}$ & $\begin{array}{l}\text { Reviews focusing solely on children and adolescents (under } \\
18 \text { years of age) } \\
\text { Reviews focusing on specific populations or ethnicities. }\end{array}$ \\
\hline Intervention & $\begin{array}{l}\text { Reviews considering interventions in palliative care for any } \\
\text { palliative care group. }\end{array}$ & $\begin{array}{l}\text { Reviews not focusing on palliative care. } \\
\text { Reviews focusing on a single procedure (i.e., a focus on } \\
\text { treatment rather than palliative care) such as } \\
\text { chemotherapy, radiotherapy, surgery and other curative } \\
\text { strategies. } \\
\text { Reviews focusing on palliative care, but not on } \\
\text { interventions. } \\
\text { Reviews focusing on treatment rather than palliative care. }\end{array}$ \\
\hline $\begin{array}{l}\text { Economic outcomes: } \\
\text { Information on cost- } \\
\text { effectiveness and costs }\end{array}$ & $\begin{array}{l}\text { Reviews including any information regarding costs, } \\
\text { whether cost, cost for caregivers cost of intervention, } \\
\text { hospitalization, or general costs at end-of-life. }\end{array}$ & Reviews not including quantitative cost elements. \\
\hline Other outcomes & Resource use & - \\
\hline Language & Written in English. & Not written in English. \\
\hline
\end{tabular}




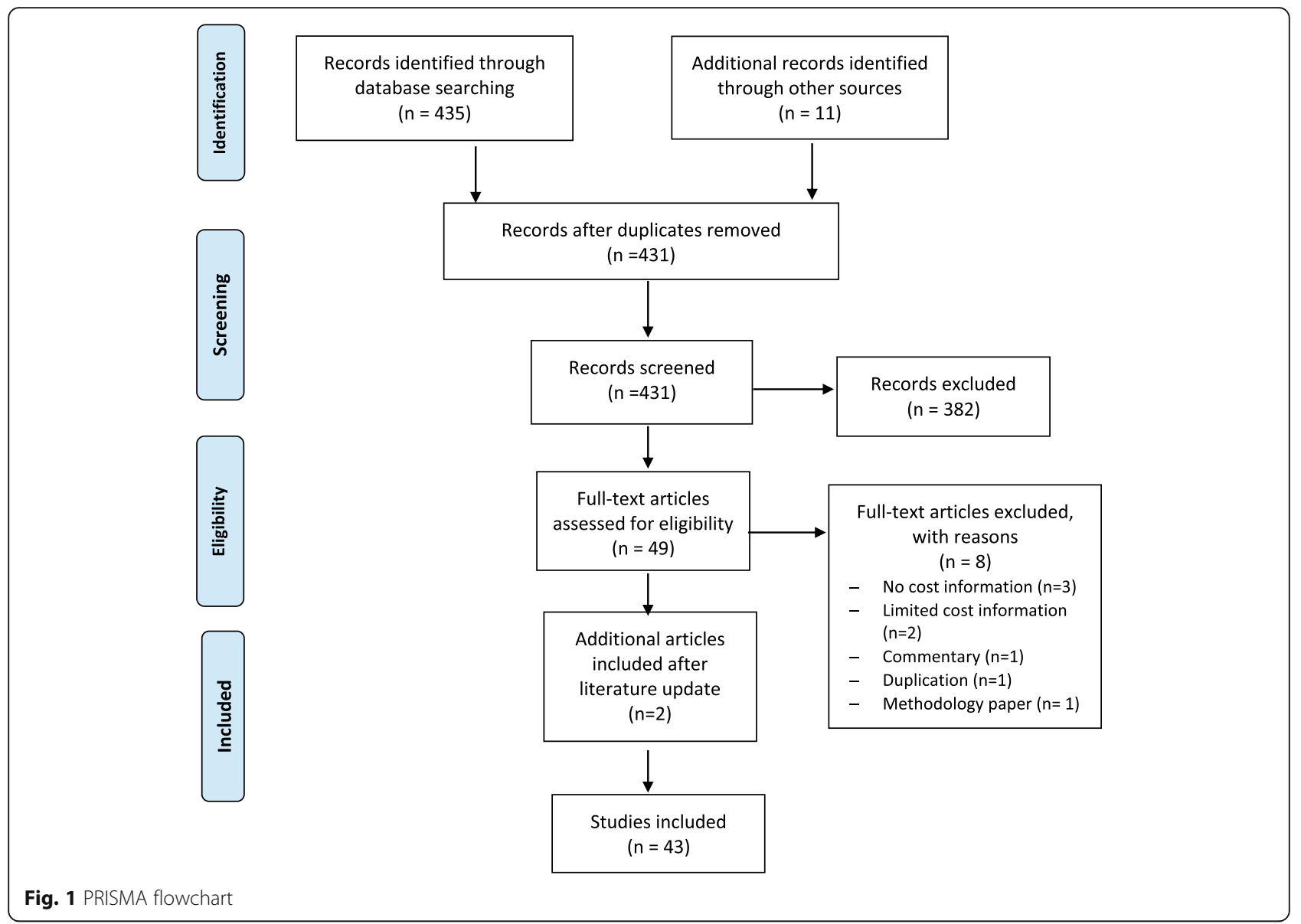

home-based interventions [24, 57, 59, 60], and 3 reviews focused on community-based interventions [61-63]. Most of the included reviews were rated as having a moderate quality (Table 3).

\section{Evidence synthesis \\ Cost-effectiveness}

In this section, we focus on studies that measured both the costs and intervention outcomes. Ideally, these components would be combined in an incremental costeffectiveness framework, following best-practice economic evaluation guidelines [64]. Such evidence is rare $[20,21]$; therefore, the evidence shown below (Table 4) also includes studies that measured both components independently. Overall, only 10 reviews included evidence on cost-effectiveness of the interventions, while the remaining 33 reviews included details on intervention costs and/or resource use.

\section{Home-based interventions}

Overall, most cost-effectiveness evidence relates to home-based interventions. One review [32] showed that home-based services may reduce resource use and costs and improve pain management and increase death outside the hospital.

Furthermore, home-based teams may generate substantial savings for the health system and improve patient outcomes. A review [47] identified 2 studies [65, 66] providing evidence of the cost-effectiveness of home-based teams for specific patient groups (i.e., cancer AIDS). A review [59] identified 6 studies of homebased palliative care, but only 2 of them provided clear evidence of cost-effectiveness. Finally, various models showed potential benefits for patients and caregivers and reduction in total healthcare costs; most such evidence pertains to home-based interventions [25].

\section{Other settings}

The remaining evidence relates to the cost-effectiveness of palliative care across multiple settings [20, 21, 25, 37, $44,54,61$ ]. A review on [61] palliative care interventions outside the home, identified two studies that included an economic evaluation $[67,68]$, but only one [68] performed a full cost-effectiveness analysis of the effect of psychosocial support on survival in women with breast cancer. No significant difference in healthcare resource use between the intervention and control groups was 


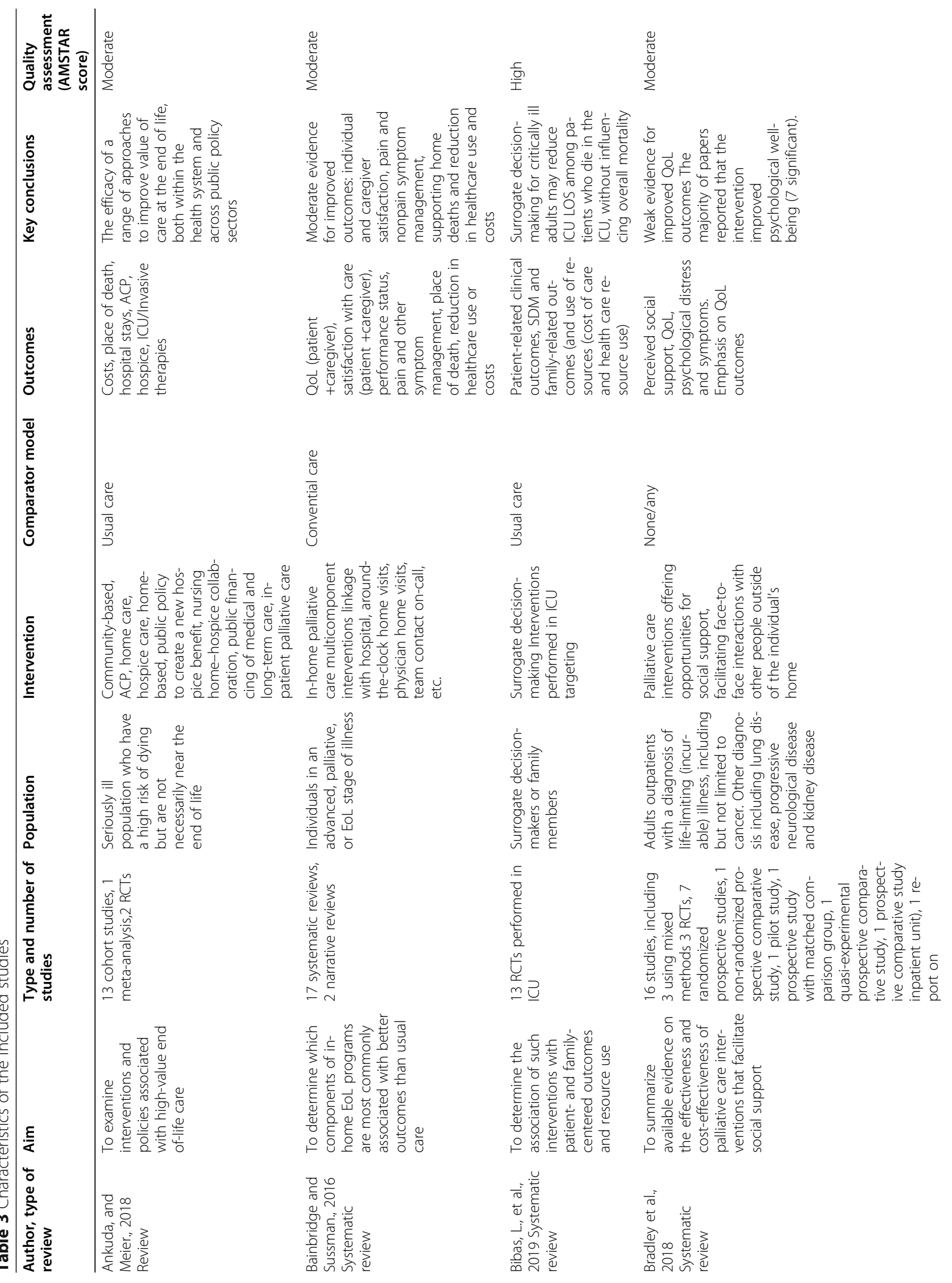




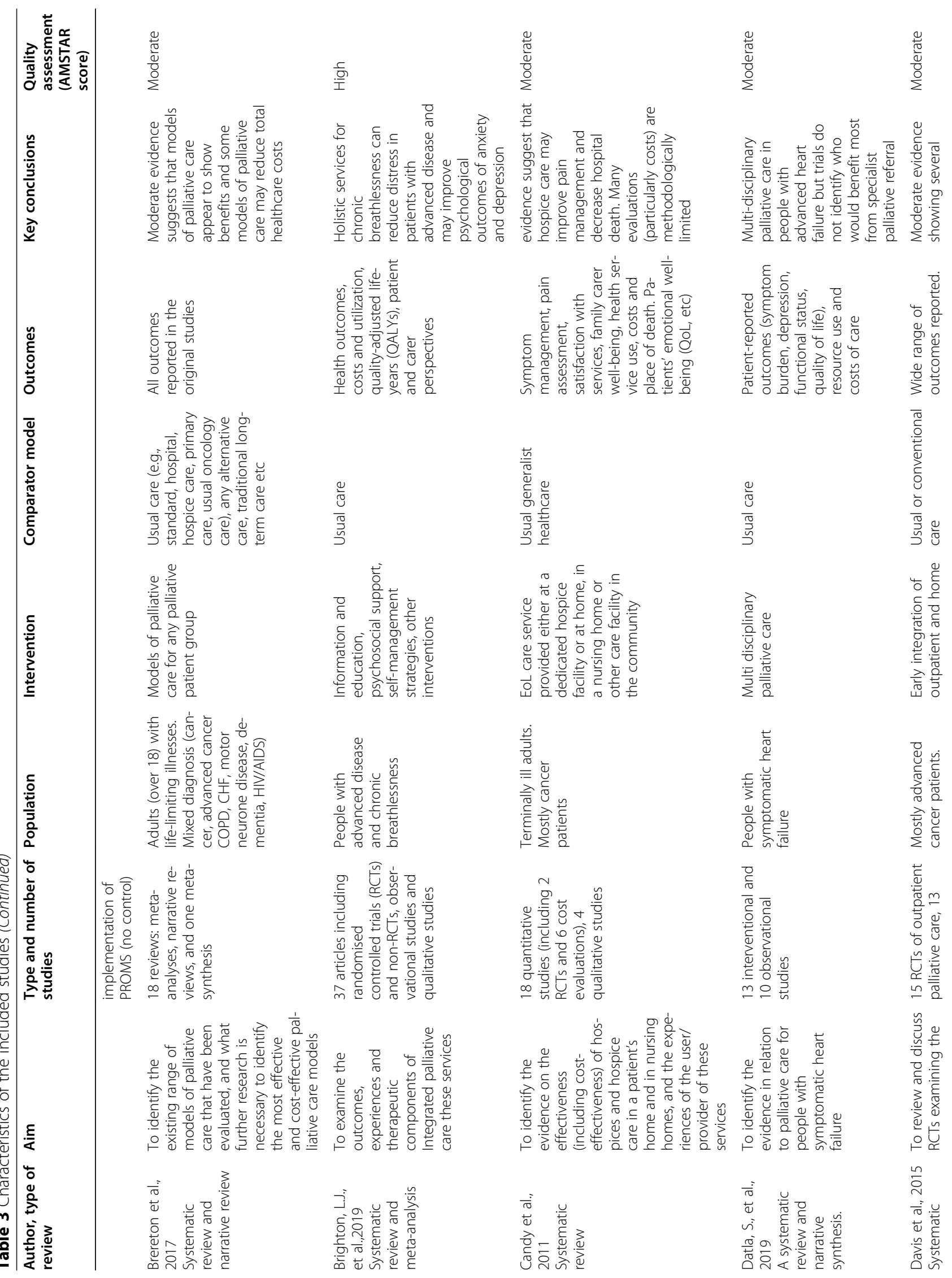




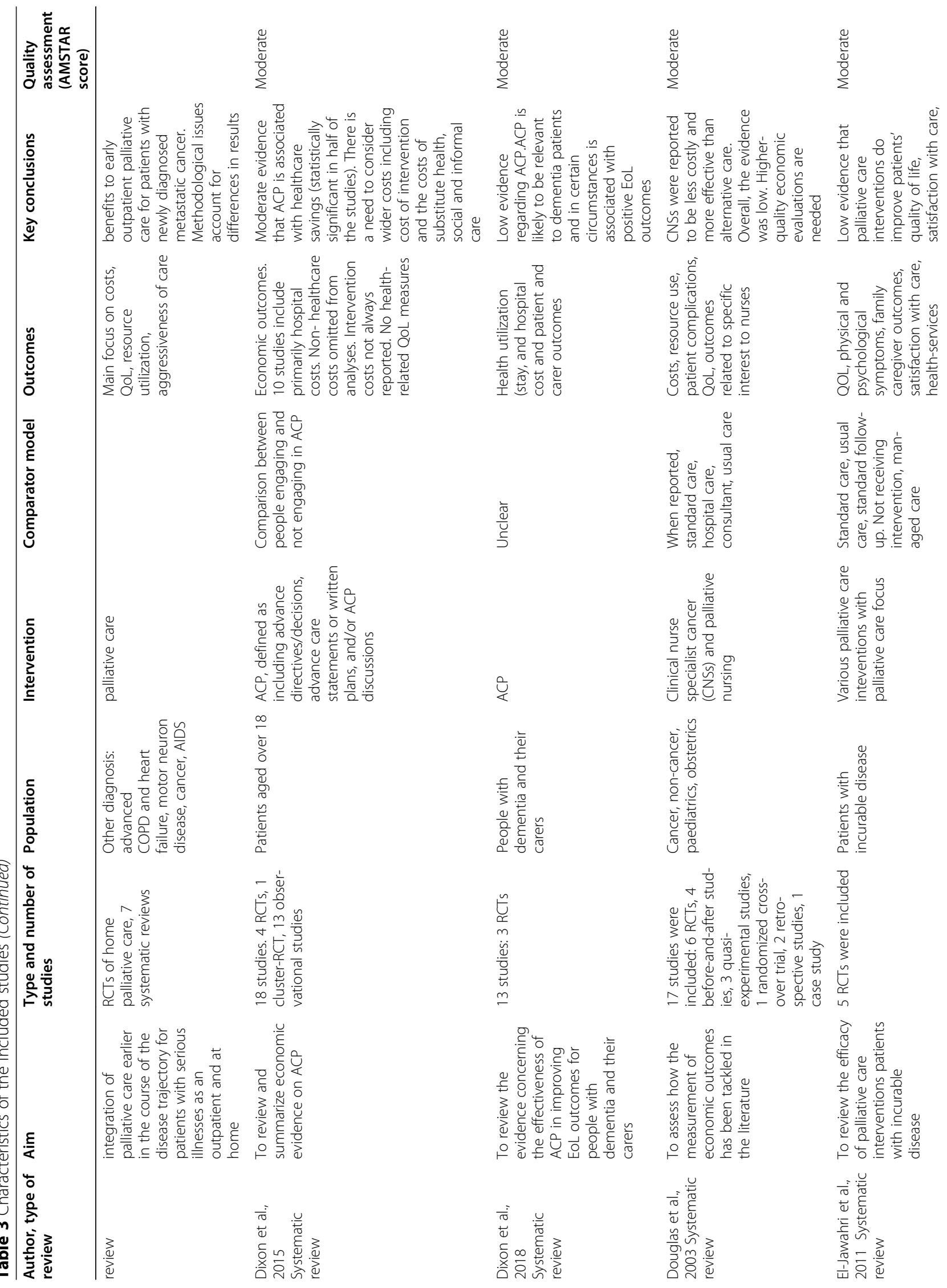




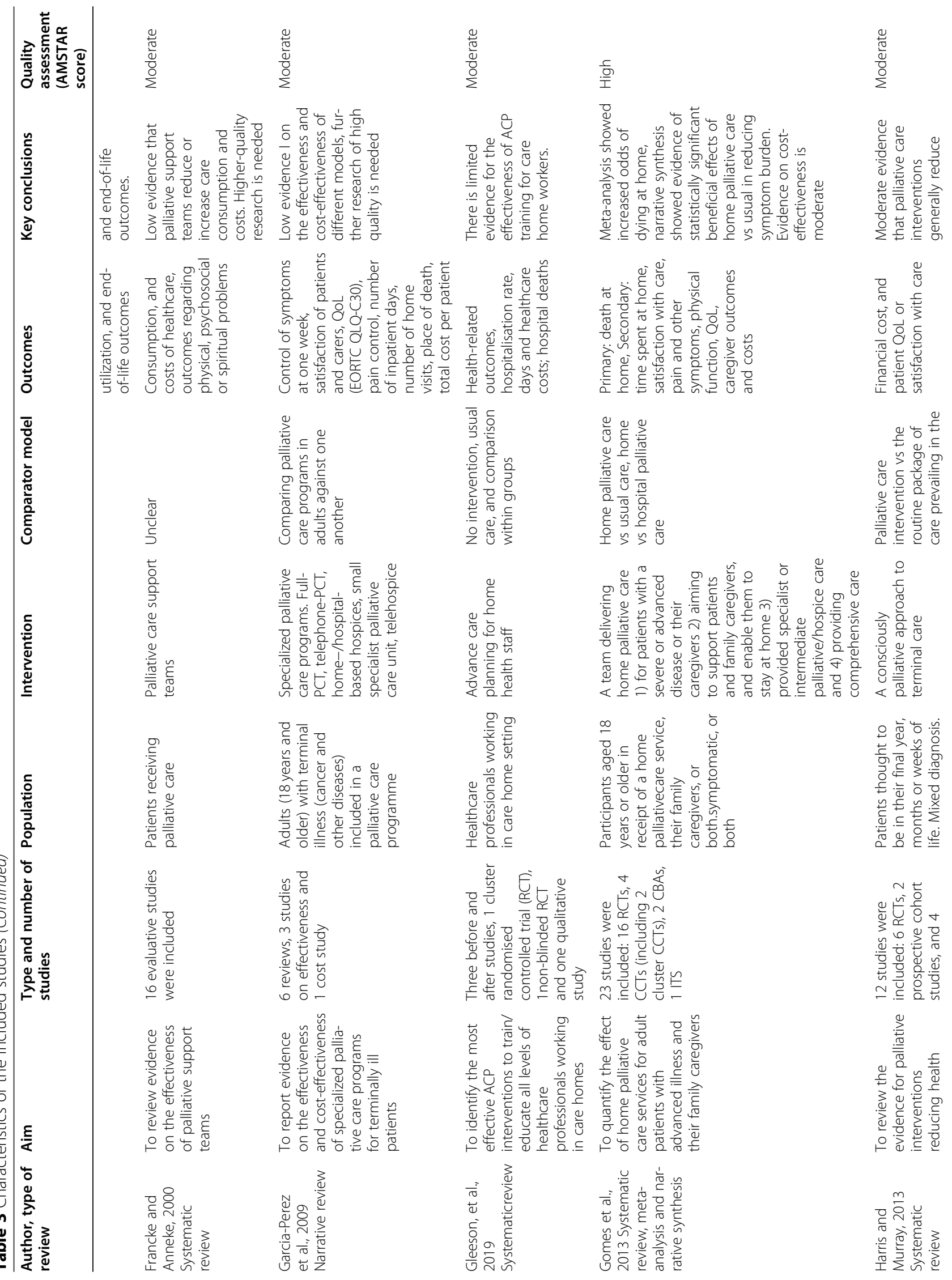




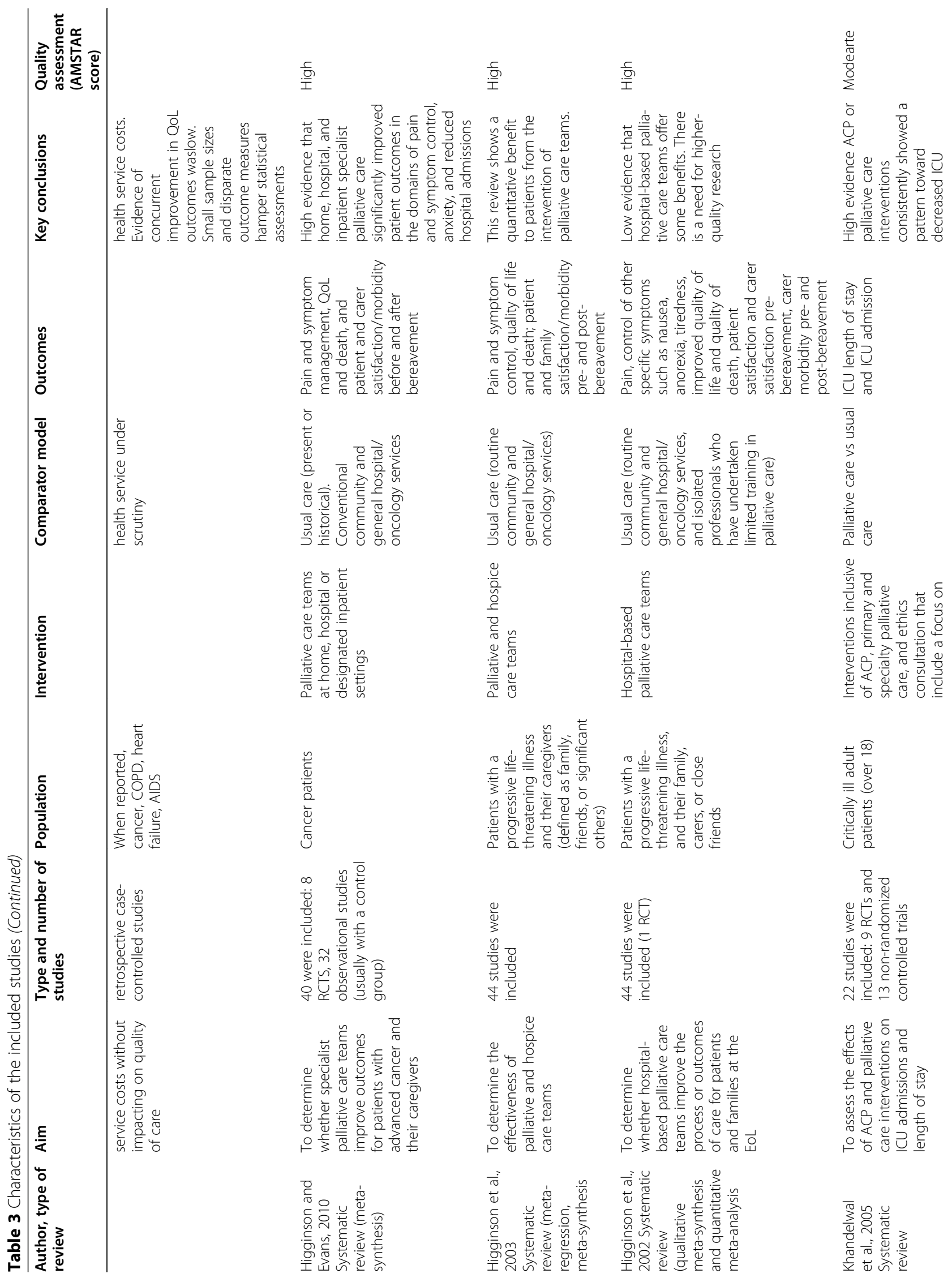




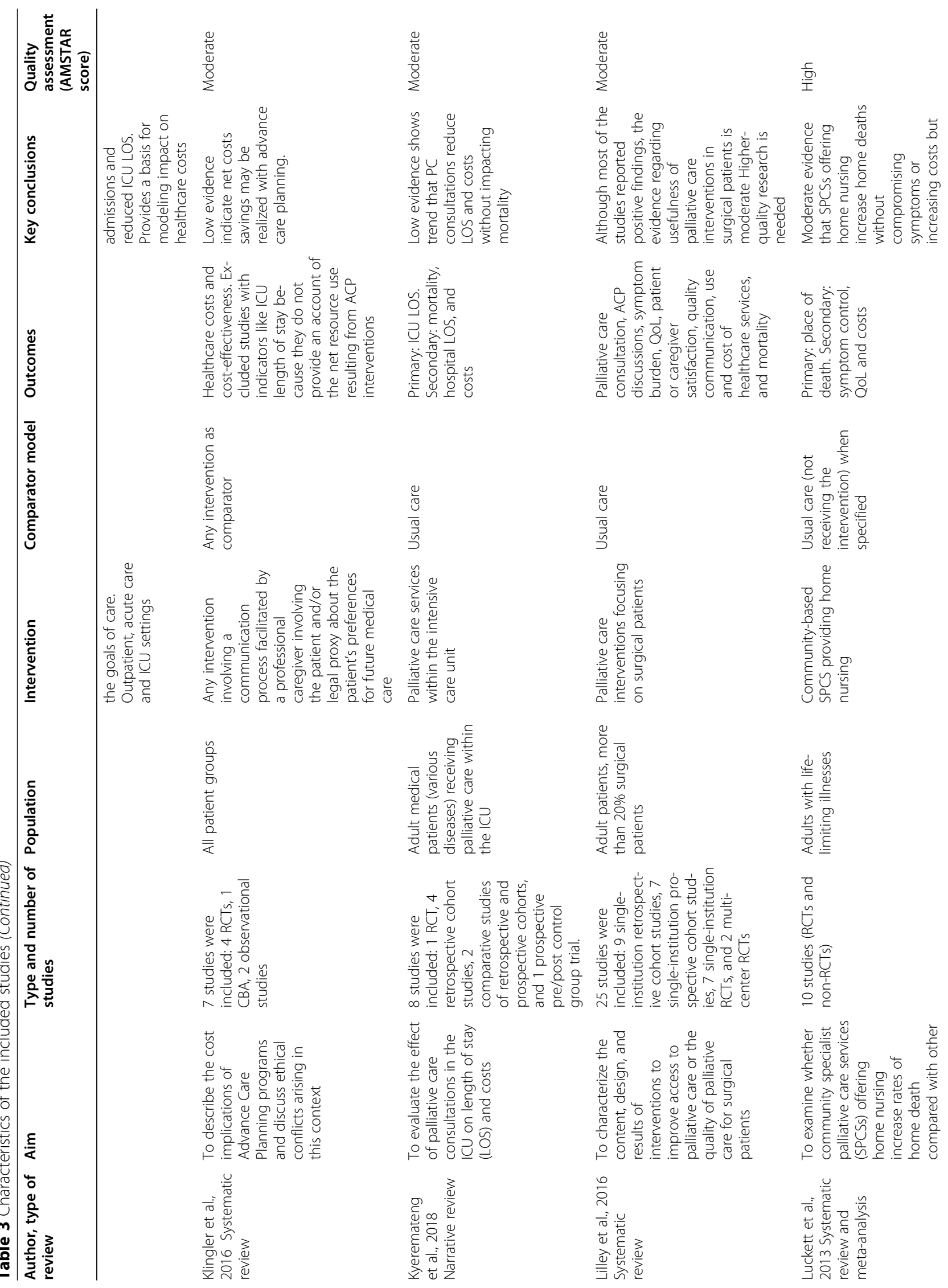




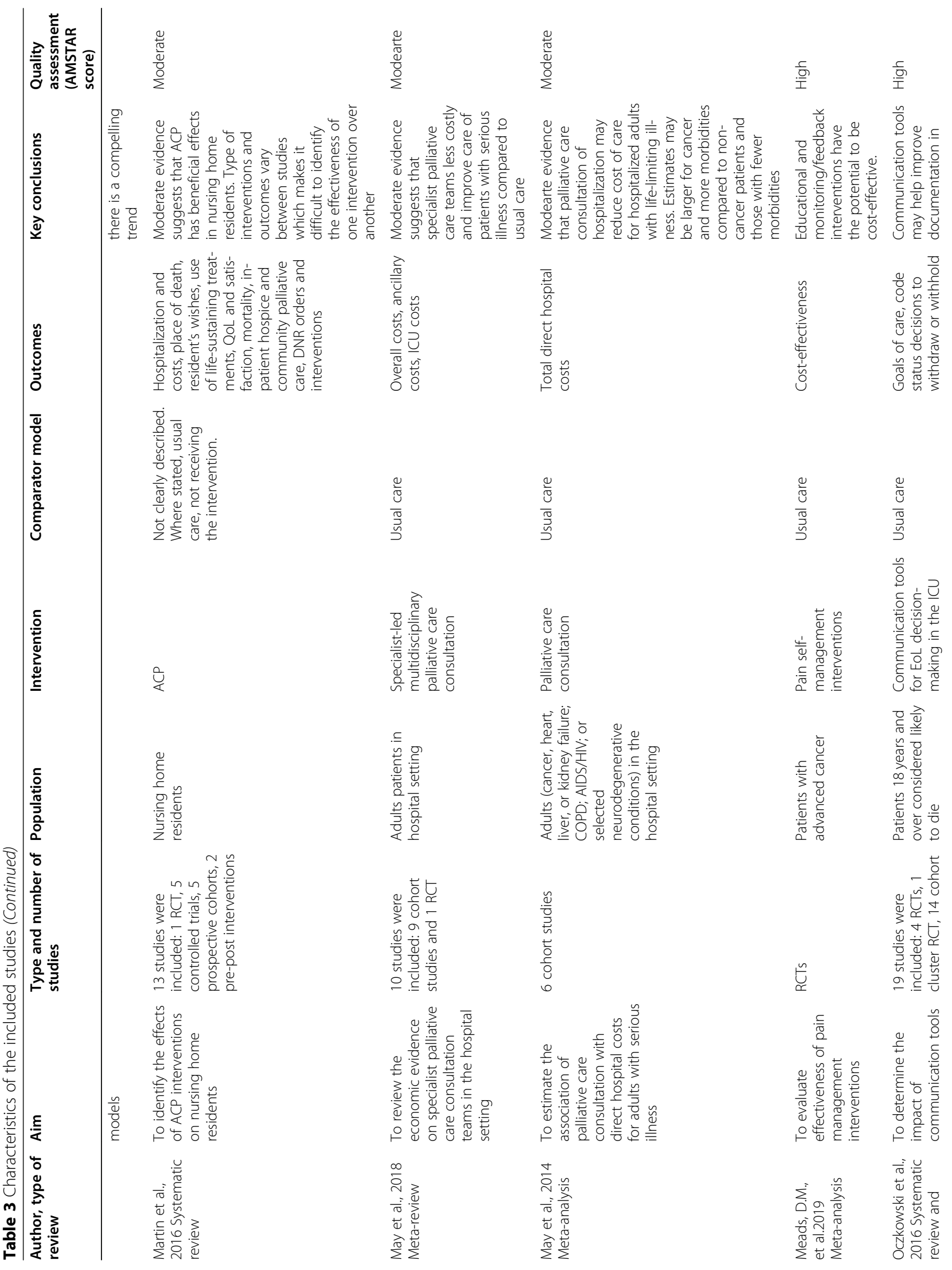




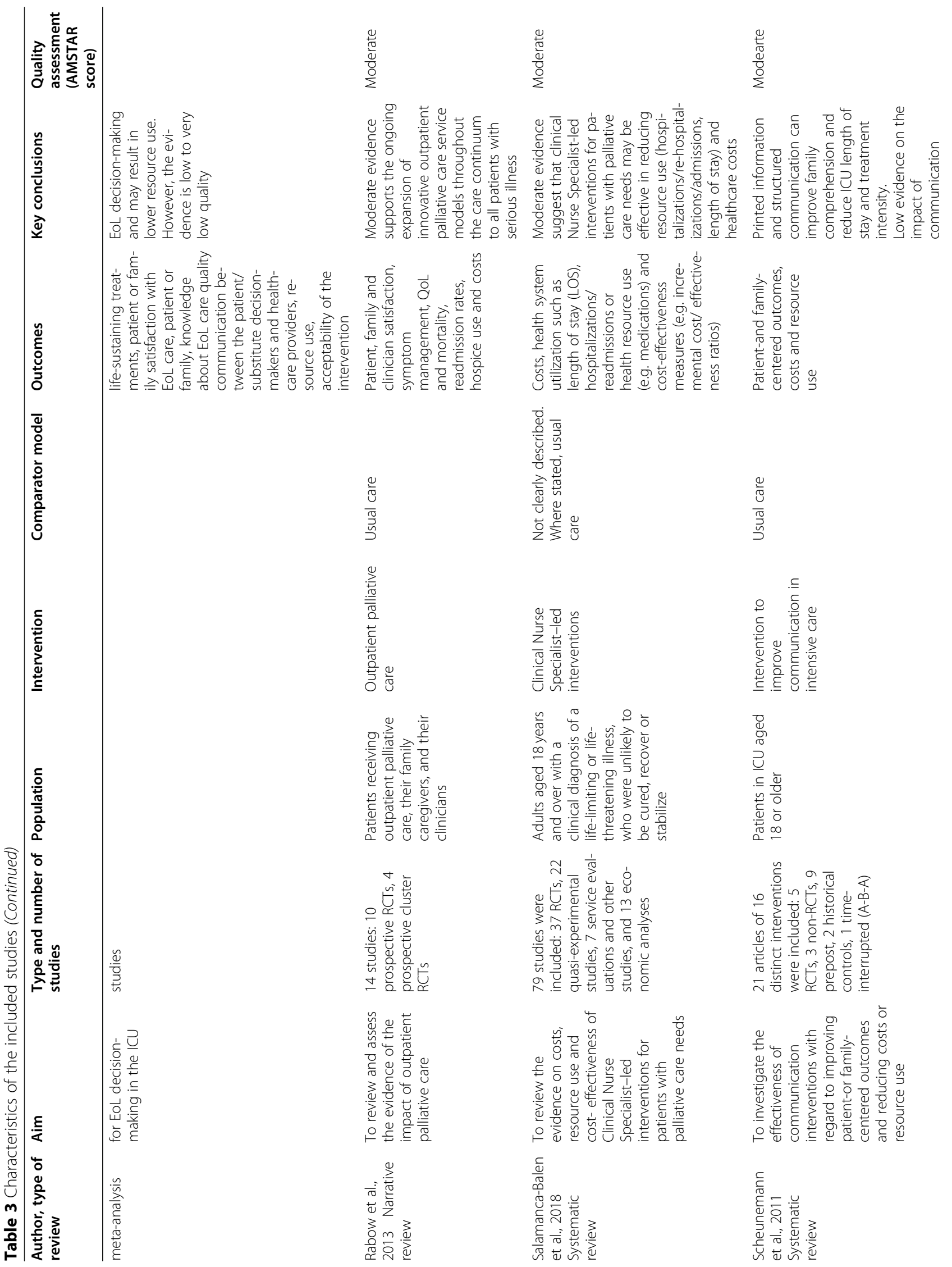




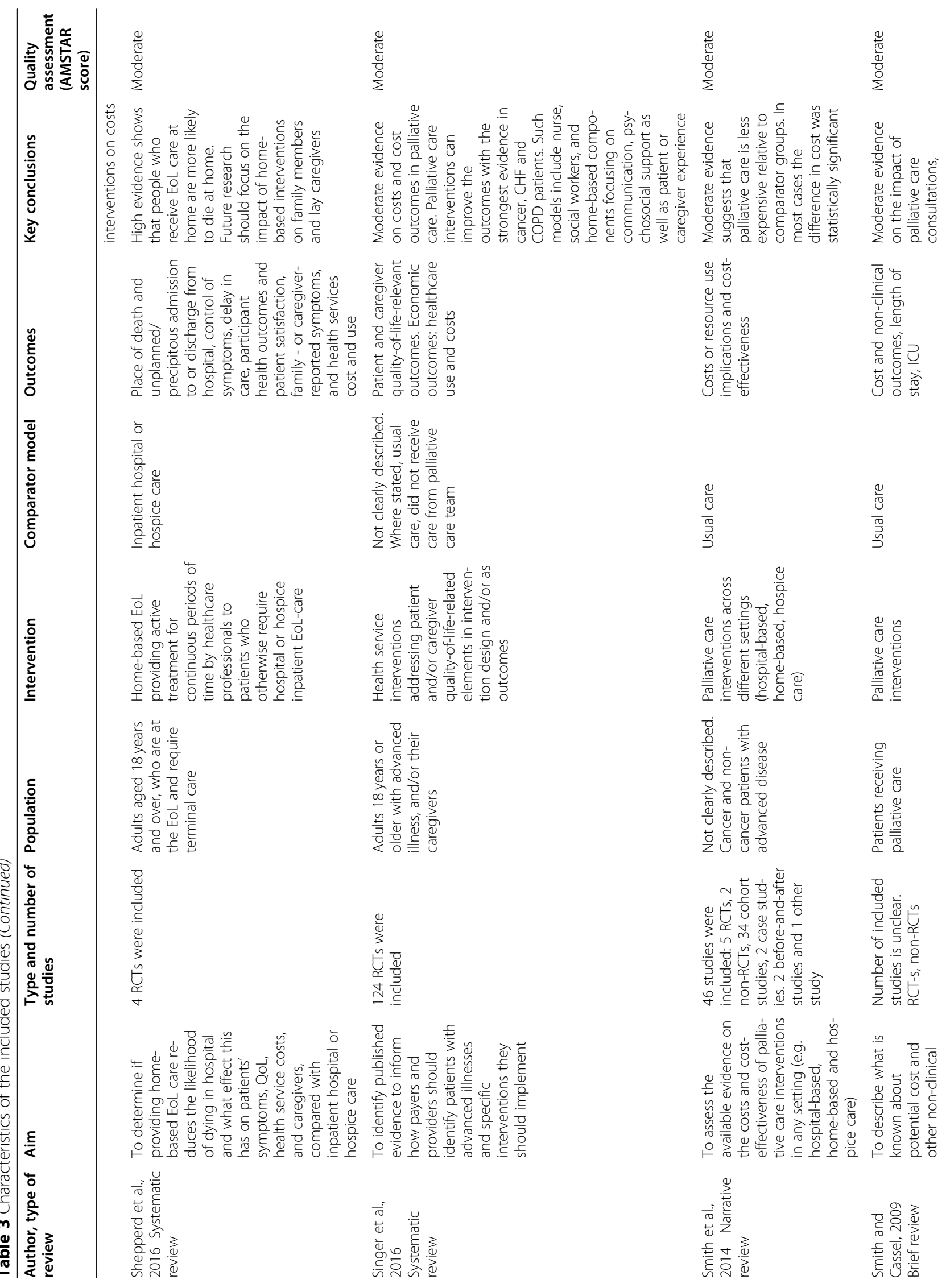




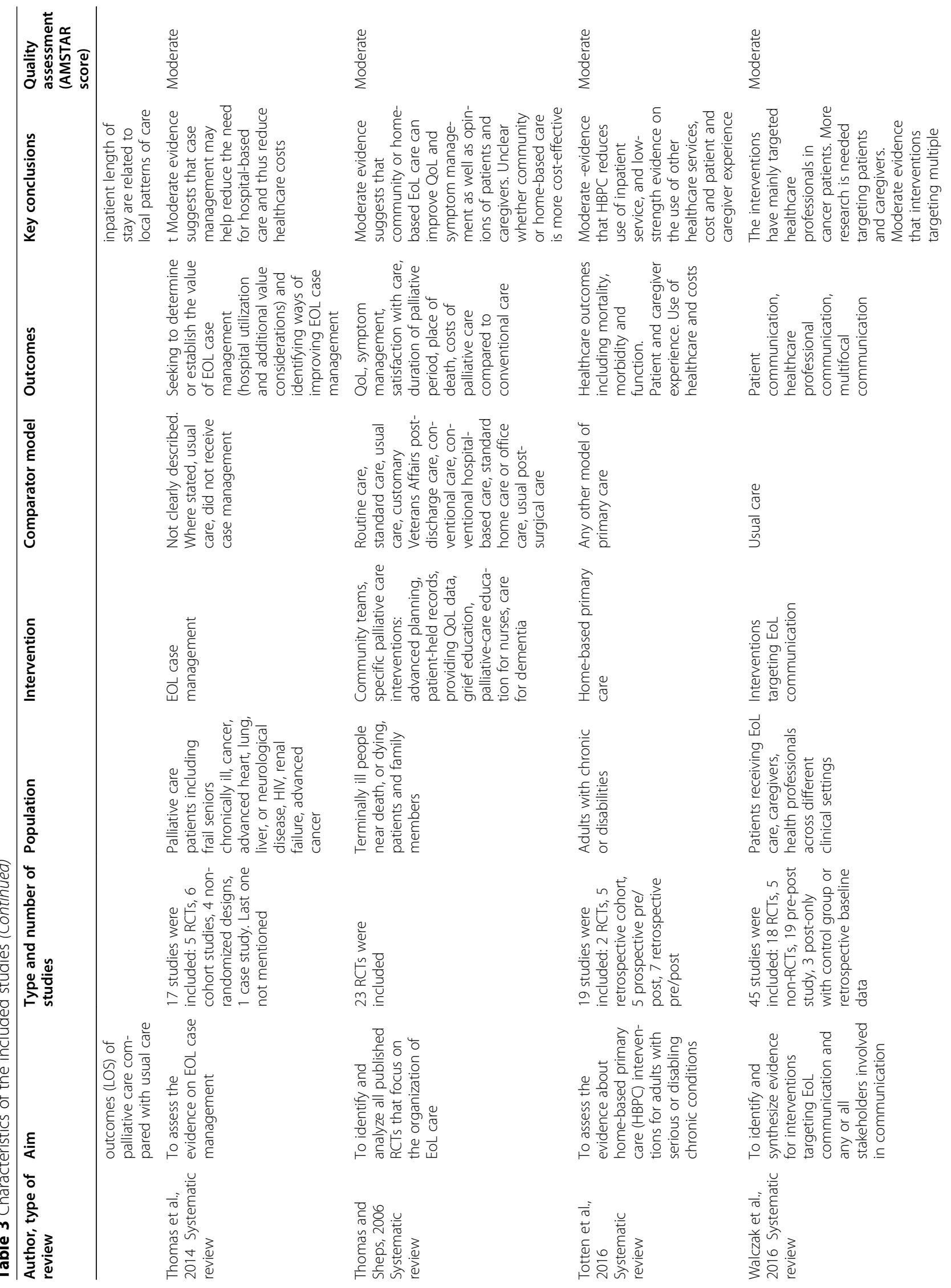




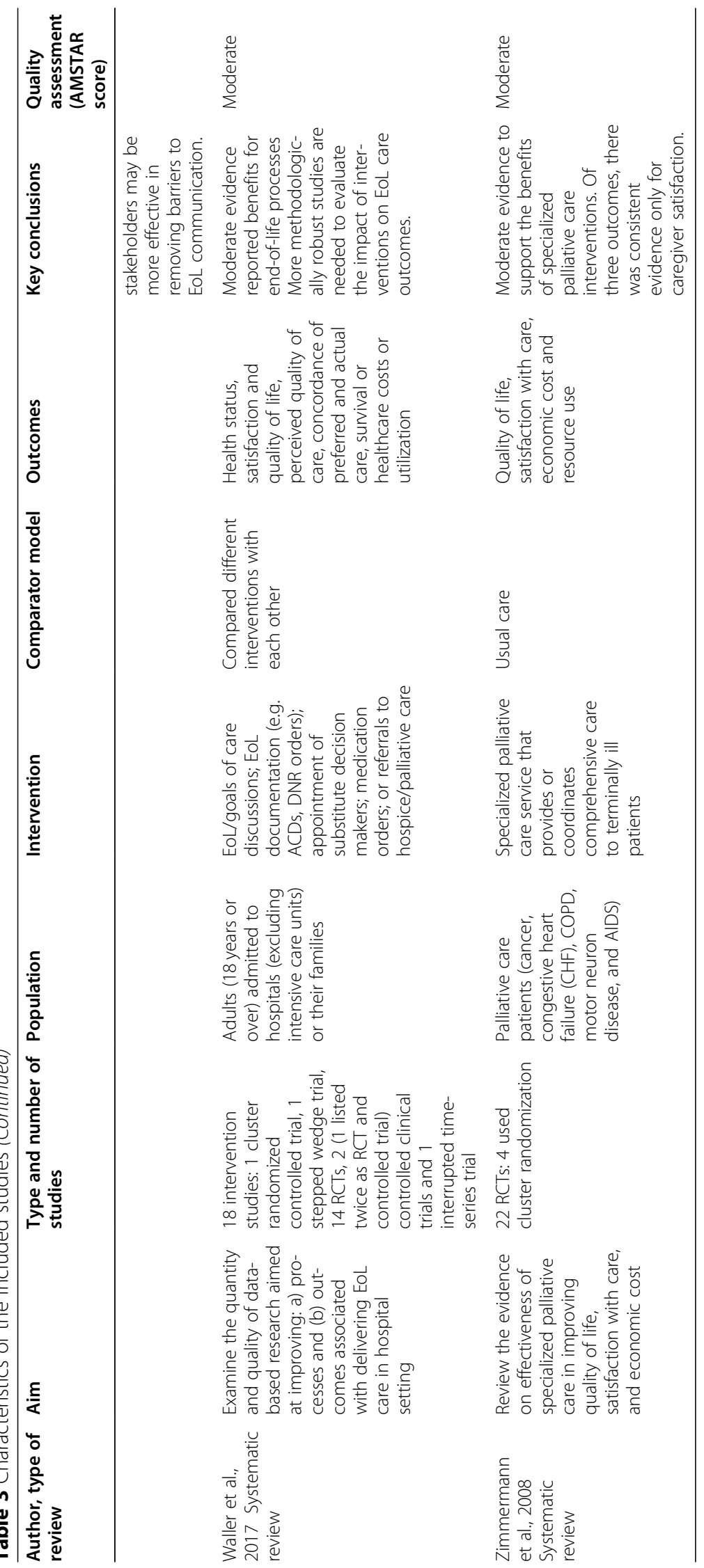


Table 4 Studies reporting on cost-effectiveness of palliative care interventions

\begin{tabular}{|c|c|c|}
\hline Author & Cost-effectiveness & Type of intervention \\
\hline $\begin{array}{l}\text { Ankuda, and } \\
\text { Meier., } 2018\end{array}$ & $\begin{array}{l}\text { Reported benefits of palliative care consultations on patient outcomes, use of healthcare } \\
\text { and costs. }\end{array}$ & $\begin{array}{l}\text { Hospital-based palliative care } \\
\text { consultations }\end{array}$ \\
\hline $\begin{array}{l}\text { Bradley et al., } \\
2018\end{array}$ & $\begin{array}{l}\text { Reported some evidence of cost-effectiveness of psychosocial support on survival in } \\
\text { women with breast cancer. No significant difference in healthcare resource use between } \\
\text { the intervention and control groups was found. }\end{array}$ & Clinical nurse specialists \\
\hline $\begin{array}{l}\text { Brereton et al., } \\
2017\end{array}$ & $\begin{array}{l}\text { Various home-based interventions showed benefits for patients and caregivers and reduced } \\
\text { healthcare costs. }\end{array}$ & Home-based \\
\hline $\begin{array}{l}\text { Candy et al., } \\
2011\end{array}$ & $\begin{array}{l}\text { Hospice care interventions reduce resource use and costs, improve pain management, and } \\
\text { increase death outside the hospital. }\end{array}$ & $\begin{array}{l}\text { Hospice care at home, nursing } \\
\text { homes and hospice facilities }\end{array}$ \\
\hline $\begin{array}{l}\text { Douglas et al., } \\
2003\end{array}$ & $\begin{array}{l}\text { Reported lower costs and greater benefits of CNSs compared to usual care. Evidence of } \\
\text { cost-effectiveness of pain management strategies in advanced cancer patients. }\end{array}$ & Clinical nurse specialists \\
\hline $\begin{array}{l}\text { Gomes et al., } \\
2013\end{array}$ & $\begin{array}{l}\text { Reported clear cost-effectiveness of home-based interventions compared to usual care in } 2 \\
\text { studies. }\end{array}$ & Home-based \\
\hline $\begin{array}{l}\text { Higginson et al., } \\
2003\end{array}$ & $\begin{array}{l}\text { Evidence of the cost-effectiveness of home-based teams for specific patient groups includ- } \\
\text { ing cancer and AIDS. }\end{array}$ & Home-based \\
\hline $\begin{array}{l}\text { Meads, D.M., } \\
\text { et al.2019 }\end{array}$ & $\begin{array}{l}\text { Evidence from RCTs Educational and monitoring/feedback interventions have the potential } \\
\text { to be cost-effective in patients with advanced cancer. }\end{array}$ & Hospital-based \\
\hline $\begin{array}{l}\text { Salamanca-Balen } \\
\text { et al., } 2018\end{array}$ & $\begin{array}{l}\text { Inconclusive evidence suggesting cost-effectiveness of CNS interventions including im- } \\
\text { provement in health economic outcomes, mainly in cardiac patients (heart failure) in } \\
\text { Austria, UK and Netherlands. }\end{array}$ & Clinical nurse specialists \\
\hline Smith et al., 2014 & $\begin{array}{l}\text { Reported one cost-effectiveness that showed short-term palliative care in multiple sclerosis } \\
\text { patients showed d potential cost-effectiveness when caregiver burden was used as the } \\
\text { main outcome measure. }\end{array}$ & Short-term palliative care \\
\hline
\end{tabular}

found. Smith et al. (2014) [20] identified one costeffectiveness study on short-term palliative care in multiple sclerosis patients; it suggested potential costeffectiveness when caregiver burden was used as the main outcome measure [69]. Salamanca et al. (2018) [37] provided inconclusive evidence on the costeffectiveness of clinical nurse specialists (CNSs): of 13 economic analyses, 7 reported improvement in health economic outcomes, mainly in cardiac patients. CNSs were cost-effective in several countries. In Austria home-based CNSs were both cost-effective and less expensive than standard care for HF patients [70]. In the United Kingdom, CNSs for heart disease patients generated an incremental cost of $£ 13,158$ per qualityadjusted life year (QALY) gained compared to the control group [71]. In England CNS intervention improved QoL and reduced readmissions and costs in HF patients [72]. Similarly, a study in the Netherlands CNSs improved health outcomes of patients with severe $H F$, with a slight increase in costs [73]. Douglas et al. [44] found that CNSs had lower costs and greater benefits than comparator. A review [74] on cost-effectiveness of pain management strategies in advanced cancer found that PainCheck and Tackling Cancer Pain Toolkit [TCPT] were cheaper (respective incremental costs -GBP148 [-EUR168.53] and -GBP474 [-EUR539.74]) and more effective (respective incremental QALYs of 0.010 and 0.013) than usual care.
Two other reviews reported some evidence on the benefits of hospital-based palliative care consultations on patient outcomes, healthcare utilization and cost [54, 75]. Finally, a review by Dixon et al. (2015 [21] found no evidence on cost-effectiveness of ACP.

\section{Cost analyses}

The following studies reported on the cost and resource use implications of palliative care with various degrees of comprehensiveness. Some were limited to intervention cost while others compared total healthcare costs between an intervention and a control group. Five reviews reported the cost of home-based palliative interventions [31, 76] [24, 59, 60]. Among those, 1 [76] found significant improvement in healthcare use or costs in 16 of $21(76 \%)$ studies that reported those outcomes; the majority of evidence was obtained from quasiexperimental designs. Similarly, Gomes et al. (2013) [59] showed lower costs for home-based group compared with usual care (18 to 35\%). Institutional and noninstitutional costs, medications costs and in 1 study, informal care costs, were reported. Other reviews found relatively low-quality and inconsistent evidence that home-based interventions might reduce healthcare costs $[24,60,77]$, and the costs included varied across studies.

Seven reviews reported the costs of hospital-based interventions [43, 51-57]. Of these, 3 focused on the ICU [51-53], and 1 on the surgical setting [57]. Four reviews [51, 54-56] examined the cost of inpatient palliative care 
consultations. Specifically, Kyeramateng et al. (2018) [51] showed that palliative care consultations in the ICU reduced LOS and costs, with 5 studies reporting a decrease in ICU cost and 5 others reporting a decrease in total hospital costs. Another study [55] showed that consultation delivered within 3 days of hospitalization may reduce the costs of care, mainly in cancer and multimorbid patients. Similarly, in May et al. (2014) [56], consultation teams were consistently found to be less costly (by 9-25\% for hospital costs) compared to usual care, while 1 study estimated a $32 \%$ reduction in all healthcare costs over 6 months post discharge. Another study [54] identified some evidence of lower costs in patients receiving consultations. Lilley et al. (2016) [57] found limited evidence regarding interventions to improve access to palliative care (i.e., pain and non-pain symptoms, ACP) in surgical patients. The evidence regarding cost implications of communication interventions was inconclusive $[52,53]$.

Many studies $(n=15)$ reported mixed findings on the costs of interventions in multiple settings $[20,21,23,25$, 30-42]. Smith et al. (2014) [20] found consistent evidence that palliative care is less costly relative to comparators, with statistically significant differences in most cases. Four RCTs found lower costs for palliative care. Most studies overlooked out-of-pocket and informal care costs. Salamanca-Balen et al. 2018 [37] found mixed evidence regarding the impact of CNS-led interventions on costs, with $13 / 46(28 \%)$ studies showing statistically significant cost reductions and 6/46 (13\%) studies showing significant cost increases. Bibas et al. 2019 [78] found one CSN-led intervention that observed a significant reduction in costs ( $\$ 75,850$ control vs $\$ 51060)$.

Similarly, Harris et al. (2013) [34] found statistically significant evidence suggesting that palliative care interventions may impact healthcare costs (ranging from a $77 \%$ reduction to a $9 \%$ cost increase). Seven reviews provided inconclusive evidence regarding cost reduction for specific interventions, including social support [61], CNSs [44], case management [39], communication [41], specialized palliative care [42], palliative and hospice care teams [47], multidisciplinary palliative care interventions [79] and patient and/or caregiver QoL [38].

The evidence regarding the impact of ACP on costs is limited. One review [21] showed savings ranging from USD 64,827 to USD 56,700 in total healthcare costs over 6 months. Klinger et al. (2016) [23] reported net cost savings ranging from USD 1041 to USD 64,830 per patient (relative cost reduction 68 to 5\%), with the greatest reductions found for sicker patients. Martin et al. (2016) [62] found limited evidence of impact on costs in 1 study [80] suggesting a significant decrease in both hospital costs and total healthcare costs [81]. Another study [63] identified cost savings for patients with severe dementia who received $\mathrm{ACP}$ in the community [82] and for care home residents [80]. Another study [83] on ACP for home health staff reported showed significant reductions in hospitalisation rate, days and healthcare cost.

\section{Impact on resource use}

Five studies [24, 30-32, 36, 38, 60, 76] examined the impact of home-based interventions on resource use. Bainbridge et al. (2016) [76] showed a significant reduction in healthcare use in the home care group. Other reviews found inconclusive evidence regarding the impact of home-based interventions on resource use, including general healthcare utilization [32], LOS and hospitalizations $[24,31,38,60]$.

Candy et al. (2011) [32] showed that patients receiving hospice care at home had lower healthcare utilization. The strength of this evidence, however, was limited because few of the findings originated from RCTs. Davis et al. (2015) [31] showed that early integration of outpatient and home palliative care may reduce LOS and hospitalizations. In another study [60], it was unclear whether home-based care impacts hospital admissions. Admission to hospital while receiving home-based care varied among trials. One study [38] found that palliative interventions $(65 \%, 11$ of 17$)$ reduced hospital use and that home interventions were more effective than other interventions in cancer, COPD and dementia patients.

Evidence regarding the impact of hospital-based palliative care interventions was scarce. One review [58] suggested that hospital-based palliative care may have a positive impact on resource use (i.e., reduced hospitalizations). Two reviews showed a reduction in ICU LOS for intervention patients receiving inpatient palliative care consultations compared with control patients [50, 51]. Two other reviews found that communication interventions may decrease healthcare resource use in multiple dimensions, including duration of mechanical ventilation [53] and hospital and ICU LOS [41, 52, 53]. Waller et al. (2017) [54] found limited evidence that hospital-based interventions improved processes and outcomes, with only 1 study reporting longer hospice stays.

Nine reviews reported inconsistent findings on resource use across multiple settings. Three reviews found limited evidence that palliative care interventions, including case management [20], decreased resource use, $[20,43,45]$ and improved hospice use. The evidence on effects of specialized palliative care is sparse, with 3 reviews reporting fewer hospitalizations [22, 33] and higher hospice use [42] in the intervention group. Some evidence showed that CNS might reduce hospitalizations, rehospitalizations/admissions, and LOS [37, 44, 78]. Outpatient palliative care decreased healthcare 
utilization, including ambulatory care, physician visits, hospitalizations, LOS and readmissions [49]. Datla et al. (2019) [79] reported reduction in health care resource use as a result of multi-disciplinary palliative interventions in patients with symptomatic heart failure.

$\mathrm{ACP}$ and palliative care interventions consistently demonstrated a trend toward decreased ICU admissions and reduced ICU and hospital LOS $[35,83]$. The mean relative risk reduction in the percentage of admissions with ACP and palliative care consultations was 37\%. These findings were supported by two other reviews showing decreased hospitalization rates [62] among patients receiving ACP, including dementia patients [63].

\section{Discussion}

The strongest evidence of cost-effectiveness relates to home-based interventions, suggesting high potential efficiency gains for the health system through a decrease in total healthcare costs and resource use and improvements in patient and caregiver outcomes. The evidence of interventions in other settings was inconsistent. There was some evidence suggesting potential benefits of CNS interventions for patients with heart disease. Overall, the majority of studies focused on cancer patients. One explanation is that disease trajectories for cancer are less heterogeneous than for other diseases $[80,81]$ and that the end-of-life phase is easier to predict in this patient group [84].

Our findings reveal a potential for reduction in direct healthcare costs and resource use mainly in home-based programs. Inpatient palliative care consultations were consistently associated with fewer hospitalizations, readmissions and reduced costs. We found some evidence of the effectiveness of ACP for reducing resource use. Such interventions have been considered important, especially for dementia patients [85]; however, further research is needed regarding the effectiveness and cost-effectiveness of ACP interventions.

Overall, most studies overlooked important costs, including out-of-pocket, hospice and informal care costs. It is important that future studies systematically report these to get a comprehensive understanding of the health economic implications of palliative and end-oflife care, despite the complexity of their measurement and valuation [86]. Another issue is the lack of consistency in outcomes measurement that hinders comparability across studies. While quality-adjusted life years (QALYs) are widely used in cost-effectiveness, they are limited in their ability to capture the benefits of endof-life and palliative care. Tools that have been developed to measure wellbeing in the broader sense should be more widely used [87, 88]. More generally, future economic studies in the area should more systematically follow existing economic evaluation guidelines and adopt a societal perspective.

\section{Strengths and limitations}

An important strength of this study is the focus on the economic value of a wide range of interventions. The effectiveness of palliative care interventions has been studied previously, but the focus on cost-effectiveness, resource use and costs has been scarce [25, 89]. By conducting this review of reviews we believe that we have identified the main sources of (high-quality) evidence. This work has several limitations. One key challenge was related to the wide range of settings and intervention types included as well as the diversity of reporting of findings across reviews (e.g., outcome measurement, costing approaches, etc.). While a broad inclusion was a deliberate feature of our study, it made the synthesis of evidence difficult. Most approaches focused on the hospital setting. Hospital costs are known to escalate in the last phase of life, with questionable benefit to patients $[90,91]$. Furthermore, the evidence is subject to a range of methodological limitations as discussed above. Also, as evidence often comes from retrospective data important information (e.g., patient preferences) were not be available [92].

\section{Conclusions}

Home-based palliative care may contribute to a dual improvement in quality of care by reducing aggressive medicalization end-of-life and concomitantly reducing costs. Hospital-based palliative care interventions may improve patient outcomes, healthcare utilization and costs. Evidence regarding other approaches is less conclusive. This study provides a foundation for discussions between policy makers and clinical services managers regarding resource allocation and the commissioning of palliative care services. There is a need for greater consistency in costs and outcome measures reporting, including breadth of capture (e.g., informal care costs, hospice costs, better-suited measure of patient outcomes, etc.). In addition, as RCTs are rarely feasible in the area, a particular focus on the quality of observational, and quasi-experimental evidence, is warranted. On the clinical side, further examination of who can deliver interventions is important for clinical practice can generalists (non palliative care specialists) deliver these interventions as well as specialists? What are the enablers and barriers to successful interventions? Also, information on timing in relation to death would be useful to understand more fully the impact and resource implications of palliative care interventions. Research that addresses these practical issues as well as examining effectiveness and cost would help policy makers and clinical teams know where to invest resources. Better 
patient care can be provided at lower costs for people in the last phase of life with intentional palliative care interventions.

\section{Abbreviations}

ACP: Advance care planning; CNS: Clinical nurse specialist interventions; ICU: Intensive care unit; LOS: Length of stay; QOL: Quality of life

\section{Acknowledgments}

The authors would like to thank Thomas Brauchli for the support in literature search.

\section{Authors' contributions}

$\mathrm{BO}$ and $\mathrm{XL}$ collected the data. $\mathrm{XL}$ and $\mathrm{JM}$ analyzed the data. $\mathrm{XL}$ prepared the manuscript and revisions for publication. JM PH JB BW JD JL provided critical feedback. All authors read and approved the final manuscript.

\section{Funding}

This work was supported by the Health Foundation (www.health.org.uk). The funders had no role in study design, data collection and analysis, decision to publish, or preparation of the manuscript.

\section{Availability of data and materials}

Data sharing is not applicable to this article as no datasets were generated or analysed during the current study.

\section{Declarations}

Ethics approval and consent to participate

Not applicable.

\section{Consent for publication}

Not applicable.

\section{Competing interests}

The authors declare no conflict of interest.

\section{Author details}

${ }^{1}$ Centre for Primary Care and Public Health (Unisanté), University of Lausanne, Route de la Corniche 10, CH-1010 Lausanne, Switzerland. ${ }^{2}$ Institute of Global Health Innovation, Department of Surgery and Cancer, Imperial College London, London, UK. ${ }^{3}$ Edinburgh Cancer Research Centre, University of Edinburgh, Edinburgh, UK. ${ }^{4} \mathrm{NHS}$ Fife, Scotland, UK. ${ }^{5}$ University of St Andrews, Scotland, UK. ${ }^{6}$ Harris Manchester College, University of Oxford, Oxford, UK. ${ }^{7}$ The Royal Marsden NHS Foundation Trust, London, UK.

\section{Received: 20 February 2020 Accepted: 26 May 2021}

\section{Published online: 23 June 2021}

References

1. Panczak R, Luta X, Maessen M, Stuck AE, Berlin C, Schmidlin K, et al. Regional variation of cost of Care in the Last 12 months of life in Switzerland: small-area analysis using insurance claims data. Med Care. 2017; 55(2):155-63. https://doi.org/10.1097/MLR.0000000000000634.

2. Howdon D, Rice N. Health care expenditures, age, proximity to death and morbidity: implications for an ageing population. J Health Econ. 2018;57:6074. https://doi.org/10.1016/j.jhealeco.2017.11.001

3. Tanuseputro P, Wodchis WP, Fowler R, Walker P, Bai YQ, Bronskill SE, et al. The health care cost of dying: a population-based retrospective cohort study of the last year of life in Ontario, Canada. PloS one. 2015:10(3): e0121759. https://doi.org/10.1371/journal.pone.0121759.

4. Ellershaw JE, Lakhani M. Best care for the dying patient. BMJ. 2013;347(jul12 2). https://doi.org/10.1136/bmj.f4428.

5. Harrington SE, Smith TJ. The role of chemotherapy at the end of life: "when is enough, enough?". Jama. 2008;299(22):2667-78. https://doi.org/10.1001/ja ma.299.22.2667.

6. Bekelman JE, Halpern SD, Blankart CR, Bynum JP, Cohen J, Fowler R, et al. Comparison of site of death, health care utilization, and hospital expenditures for patients dying with Cancer in 7 developed countries. Jama. 2016;315(3):272-83. https://doi.org/10.1001/jama.2015.18603.
7. Wright AA, Keating NL, Ayanian JZ, Chrischilles EA, Kahn KL, Ritchie CS, et al. Family perspectives on aggressive cancer care near the end of life. JAMA 2016;315(3):284-92. https://doi.org/10.1001/jama.2015.18604.

8. Higginson IJ. Research challenges in palliative and end of life care. BMJ Supportive Palliative Care. 2016;6(1):2-4.

9. Hui D, De La Cruz M, Mori M, Parsons HA, Kwon JH, Torres-Vigil I, et al. Concepts and definitions for "supportive care," "best supportive care," "palliative care," and "hospice care" in the published literature, dictionaries, and textbooks. Support Care Cancer. 2013;21(3):659-85. https://doi.org/10.1 007/s00520-012-1564-y.

10. Mularski RA, Puntillo K, Varkey B, Erstad BL, Grap MJ, Gilbert HC, et al. Pain management within the palliative and end-of-life care experience in the ICU. Chest. 2009:135(5):1360-9. https://doi.org/10.1378/chest.08-2328.

11. Morrison RS, Meier DE. Clinical practice. Palliative care. N Engl J Med. 2004; 350(25):2582-90. https://doi.org/10.1056/NEJMcp035232

12. Gade G, Venohr I, Conner D, McGrady K, Beane J, Richardson RH, et al. Impact of an inpatient palliative care team: a randomized control trial. J Palliat Med. 2008;11(2):180-90. https://doi.org/10.1089/jpm.2007.0055.

13. Rummans TA, Clark MM, Sloan JA, Frost MH, Bostwick JM, Atherton PJ, et al. Impacting quality of life for patients with advanced cancer with a structured multidisciplinary intervention: a randomized controlled trial. J Clin Oncol. 2006;24(4):635-42. https://doi.org/10.1200/JCO.2006.06.209.

14. Morrison RS, Dietrich J, Ladwig S, Quill T, Sacco J, Tangeman J, et al. Palliative care consultation teams cut hospital costs for Medicaid beneficiaries. Health Affairs (Project Hope). 2011;30(3):454-63. https://doi. org/10.1377/hlthaff.2010.0929.

15. O'Mahony S, Blank AE, Zallman L, Selwyn PA. The benefits of a hospital-based inpatient palliative care consultation service: preliminary outcome data. J Palliat Med. 2005;8(5):1033-9. https://doi.org/10.1089/jpm.2005.8.1033.

16. Arnold E, Finucane AM, Oxenham D. Preferred place of death for patients referred to a specialist palliative care service. BMJ Support Palliat Care. 2015; 5(3):294-6. https://doi.org/10.1136/bmjspcare-2012-000338.

17. Morris ZS, Fyfe M, Momen N, Hoare S, Barclay S. Understanding hospital admissions close to the end of life (ACE) study. BMC Health Serv Res. 2013; 13(1):89. https://doi.org/10.1186/1472-6963-13-89.

18. Romano AM, Gade KE, Nielsen G, Havard R, Harrison JH Jr, Barclay J, et al. Early palliative care reduces end-of-life intensive care unit (ICU) use but not ICU course in patients with advanced Cancer. Oncologist. 2017:22(3):318-23. https://doi.org/10.1634/theoncologist.2016-0227.

19. Trtchounian A, Aberger K, Nelson J. 292 early palliative care consultation associated with decreased length of stay. Ann Emerg Med. 2017;70(4):S115. https://doi.org/10.1016/j.annemergmed.2017.07.270.

20. Smith SB, A.O'Hara, S.Normand, C. Evidence on the cost and costeffectiveness of palliative care: a literature review. Palliat Med 2014;28(2): 130-150, DOl: https://doi.org/10.1177/0269216313493466.

21. Dixon JM, T.Knapp, M. The economic evidence for advance care planning: systematic review of evidence. Palliat Med 2015:29(10):869-884, DOl: https:// doi.org/10.1177/0269216315586659.

22. Higginson IJ, Evans CJ. What is the evidence that palliative care teams improve outcomes for cancer patients and their families? Cancer J (Sudbury Mass). 2010;16(5):423-35.

23. Klingler CS, Marckmann J, G. Does facilitated advance care planning reduce the costs of care near the end of life? Systematic review and ethical considerations. Palliat Med. 2016;30(5):423-33. https:/doi.org/10.1177/0269216315601346.

24. Totten AMW-C, E. F.Wasson, N.Morgan, E.Kansagara, D.Davis-O'Reilly, C. Goodlin, S. AHRQ Comparative Effectiveness Reviews. Home-Based Primary Care Interventions. Rockville: Agency for Healthcare Research and Quality (US); 2016.

25. Brereton LC, J.Ingleton, C.Gardiner, C.Preston, L.Ryan, T.Goyder, E. What do we know about different models of providing palliative care? Findings from a systematic review of reviews. Palliat Med 2017;31(9):781-797, DOl: https:// doi.org/10.1177/0269216317701890.

26. Smith V, Devane D, Begley CM, Clarke M. Methodology in conducting a systematic review of systematic reviews of healthcare interventions. BMC Med Res Methodol. 2011;11(1):15. https://doi.org/10.1186/1471-2288-11-15.

27. Corry M, While A, Neenan $K$, Smith V. A systematic review of systematic reviews on interventions for caregivers of people with chronic conditions. J Adv Nurs. 2015:71(4):718-34. https://doi.org/10.1111/jan.12523.

28. Moher D, Liberati A, Tetzlaff J, Altman DG, The PG. Preferred reporting items for systematic reviews and meta-analyses: The PRISMA statement. PLoS Med. 2009;6(7):e1000097. https://doi.org/10.1371/journal.pmed.1000097. 
29. Shea BJ, Reeves BC, Wells G, Thuku M, Hamel C, Moran J, et al. AMSTAR 2: a critical appraisal tool for systematic reviews that include randomised or non-randomised studies of healthcare interventions, or both. BMJ (Clinical research ed). 2017;358:j4008.

30. Baidoobonso S. Patient care planning discussions for patients at the end of life: an evidence-based analysis. Ont Health Technol Assess Ser. 2014;14(19): $1-72$.

31. Davis MPT, J. S.Balboni, T.Glare, P. A review of the trials which examine early integration of outpatient and home palliative care for patients with serious illnesses. Ann Palliat Med 2015;4(3):99-121, DOl: https://doi.org/10.3978/j. issn.2224-5820.2015.04.04.

32. Candy BH, A.Leurent, B.Davis, S.Jones, L. Hospice care delivered at home, in nursing homes and in dedicated hospice facilities: A systematic review of quantitative and qualitative evidence. Int J Nurs Stud 2011;48(1):121-133, DOI: https://doi.org/10.1016/j.jinurstu.2010.08.003.

33. Garcia-Perez LL, R.Martin-Olivera, R.Serrano-Aguilar, P.Benitez-Rosario, M. A. A systematic review of specialised palliative care for terminal patients: which model is better? Palliat Med 2009;23(1):17-22, DOl: https://doi.org/10.1177/ 0269216308099957.

34. Harris IM, S. A. Can palliative care reduce futile treatment? A systematic review. BMJ Support Palliat Care. 2013;3(4):389-98. https://doi.org/10.1136/ bmjspcare-2012-000343.

35. Khandelwal NK, E. K.Engelberg, R. A.Coe, N. B.Long, A. C.Curtis, J. R. Estimating the effect of palliative care interventions and advance care planning on ICU utilization: a systematic review. Crit Care Med 2015;43(5): 1102-1111, DOl: https://doi.org/10.1097/CCM.0000000000000852.

36. Pham BK, M. End-of-life care interventions: an economic analysis. Ont Health Technol Assess Ser. 2014;14(18):1-70.

37. Salamanca-Balen NS, J.Caswell, G.Whynes, D.Tod, A. The costs, resource use and cost-effectiveness of clinical nurse specialist-led interventions for patients with palliative care needs: A systematic review of international evidence. Palliat Med 2018;32(2):447-465, DOI: https://doi.org/10.1177/02 69216317711570.

38. Singer AEG, J. R.Kim, Y. S.Dy, S. M.Ahluwalia, S. C.Clifford, M.Dzeng, E. O'Hanlon, C. E.Motala, A.Walling, A. M.Goldberg, J.Meeker, D.Ochotorena, C. Shanman, R.Cui, M.Lorenz, K. A. Populations and interventions for palliative and end-of-life care: A systematic review. J Palliat Med 2016;19(9):995-1008, DOl: https://doi.org/10.1089/jpm.2015.0367.

39. Thomas REW, Donna M.Birch, Stephen Woytowich, Boris Examining End-ofLife Case Management: Systematic Review. Nurs Res Pract 2014;2014:14.

40. Thomas REW, D.Sheps, S. A literature review of randomized controlled trials of the organization of care at the end of life. Can J Aging 2006;25(3):271293, DOl: https://doi.org/10.1353/cja.2007.0011.

41. Walczak AB, P. N.Bu, S.Clayton, J. M. A systematic review of evidence for end-of-life communication interventions: who do they target, how are they structured and do they work? Patient Educ Couns 2016;99(1):3-16, DOI: https://doi.org/10.1016/j.pec.2015.08.017.

42. Zimmermann CR, R.Krzyzanowska, M.Rodin, G.Tannock, I. Effectiveness of specialized palliative care: a systematic review. Jama. 2008;299(14):16981709, DOl: https://doi.org/10.1001/jama.299.14.1698.

43. Arora N, Standfield L, Weston A. Systematic review of systems of palliative care; 2011

44. Douglas HR, Halliday D, Normand C, Corner J, Bath P, Beech N, et al. Economic evaluation of specialist cancer and palliative nursing: a literature review. Int J Palliat Nurs. 2003;9(10):424-8. https://doi.org/10.12968/ijpn.2003. 9.10.11900.

45. El-Jawahri A, Greer JA, Temel JS. Does palliative care improve outcomes for patients with incurable illness? A review of the evidence. J Supportive Oncol. 2011;9(3):87-94. https://doi.org/10.1016/j.suponc.2011.03.003.

46. Francke AL. Evaluative research on palliative support teams: a literature review. Patient Educ Couns. 2000;41(1):83-91. https://doi.org/10.1016/S073 8-3991(00)00118-X

47. Higginson IJ, Finlay IG, Goodwin DM, Hood K, Edwards AG, Cook A, et al. Is there evidence that palliative care teams alter end-of-life experiences of patients and their caregivers? J Pain Symptom Manag. 2003;25(2):150-68. https://doi.org/10.1016/S0885-3924(02)00599-7.

48. Luckett T, Davidson PM, Lam L, Phillips J, Currow DC, Agar M. Do community specialist palliative care services that provide home nursing increase rates of home death for people with life-limiting illnesses? A systematic review and meta-analysis of comparative studies. J Pain
Symptom Manag. 2013;45(2):279-97. https://doi.org/10.1016/j.jpainsymma n.2012.02.017.

49. Rabow M, Kvale E, Barbour L, Cassel JB, Cohen S, Jackson V, et al. Moving upstream: a review of the evidence of the impact of outpatient palliative care. J Palliat Med. 2013;16(12):1540-9. https://doi.org/10.1089/jpm.2013.01 53.

50. Smith TJ, Cassel JB. Cost and non-clinical outcomes of palliative care. J Pain Symptom Manag. 2009;38(1):32-44. https://doi.org/10.1016/j.jpainsymman.2 009.05.001.

51. Kyeremanteng KG, L. P.Thavorn, K.Heyland, D.D'Egidio, G. The impact of palliative care consultation in the ICU on length of stay: A systematic review and cost evaluation. J Intensive Care Med 2018;33(6):346-353, DOI: https:// doi.org/10.1177/0885066616664329.

52. Scheunemann LPM. MichelleCarson, Shannon S.Hanson, Laura C. randomized, controlled trials of interventions to improve communication in intensive care: A systematic review. Chest. 2011;139(3):543-54. https://doi. org/10.1378/chest.10-0595.

53. Oczkowski SJWC, Han-OhHanvey, Louise Mbuagbaw, Lawrence You, John J. Communication tools for end-of-life decision-making in the intensive care unit: a systematic review and meta-analysis. Critical Care. 2016;20(1):97.

54. Waller AD, N.Tattersall, M. H. N.Nair, B.Sanson-Fisher, R. Improving hospitalbased end of life care processes and outcomes: a systematic review of research output, quality and effectiveness. BMC Palliat Care 2017;16(1):34, DOl: https://doi.org/10.1186/s12904-017-0204-1.

55. May PN, C.Cassel, J.et al.,. Economics of palliative care for hospitalized adults with serious illness: A meta-analysis. JAMA Intern Med 2018;178(6):820-829, DOI: https://doi.org/10.1001/jamainternmed.2018.0750.

56. May PN, C.Morrison, R. S. Economic impact of hospital inpatient palliative care consultation: review of current evidence and directions for future research. J Palliat Med 2014;17(9):1054-1063, DOl: https://doi.org/10.1089/ jpm.2013.0594.

57. Lilley EJK, K. T.Johnston, F. M.Berlin, A.Bader, A. M.Mosenthal, A. C.Cooper, Z. Palliative care interventions for surgical patients: A systematic review. JAMA Surg 2016;151(2):172-183, DOI: https://doi.org/10.1001/jamasurg.2015.3625.

58. Higginson IJ, Finlay I, Goodwin DM, Cook AM, Hood K, Edwards AG, et al. Do hospital-based palliative teams improve care for patients or families at the end of life? J Pain Symptom Manag. 2002;23(2):96-106. https://doi.org/1 0.1016/S0885-3924(01)00406-7.

59. Gomes BC, N.Curiale, V.McCrone, P.Higginson, I. J. Effectiveness and costeffectiveness of home palliative care services for adults with advanced illness and their caregivers. Cochrane Database Syst Reviews. 2013(6): Cd007760.

60. Shepperd SG-B, D. C.Straus, S. E.Wee, B. Hospital at home: home-based endof-life care. The Cochrane Database Syst Reviews. 2016;2:Cd009231.

61. Bradley NL-W, M.Dowrick, C. Effectiveness of palliative care interventions offering social support to people with life-limiting illness-A systematic review. Eur J Cancer Care 2018;27(3):e12837, DOl: https://doi.org/10.1111/ ecc. 12837.

62. Martin RSH, B. Gregorevic, K. Lim, W. K. The effects of advance care planning interventions on nursing home residents: A systematic review. J Am Med Dir Assoc 2016;17(4):284-293, DOl: https://doi.org/10.1016/j.jamda.2015.12.01 7.

63. Dixon J, Karagiannidou M, Knapp M. The Effectiveness of Advance Care Planning in Improving End-of-Life Outcomes for People With Dementia and Their Carers: A Systematic Review and Critical Discussion. J Pain aSymptom Management. 2018;55(1):132-50.e1.

64. Michael F. Drummond MJS, Karl Claxton, Greg L. Stoddart, George W. Torrance. Methods for the Economic Evaluation of Health Care Programme. 4th Edition ed2015.

65. Tramarin A, Milocchi F, Tolley K, Vaglia A, Marcolini F, Manfrin V, et al. An economic evaluation of home-care assistance for AIDS patients: a pilot study in a town in northern Italy. AIDS (London, England). 1992;6(11):137783.

66. Ventafridda V, De Conno F, Vigano A, Ripamonti C, Gallucci M, Gamba A. Comparison of home and hospital care of advanced cancer patients. Tumori. 1989;75(6):619-25. https://doi.org/10.1177/030089168907500622.

67. Goodwin DM, Higginson IJ, Myers K, Douglas HR, Normand CE. Effectiveness of palliative day care in improving pain, symptom control, and quality of life. J Pain Symptom Manag. 2003;25(3):202-12. https://doi.org/10.1016/ S0885-3924(02)00688-7. 
68. Goodwin PJ, Leszcz M, Ennis M, Koopmans J, Vincent L, Guther H, et al. The effect of group psychosocial support on survival in metastatic breast cancer. N Engl J Med. 2001;345(24):1719-26. https://doi.org/10.1056/NEJMoa011871.

69. Higginson IJ, McCrone P, Hart SR, Burman R, Silber E, Edmonds PM. Is shortterm palliative care cost-effective in multiple sclerosis? A randomized phase II trial. J Pain Symptom Manag. 2009;38(6):816-26. https://doi.org/10.1016/j. jpainsymman.2009.07.002.

70. Adlbrecht C, Huelsmann M, Berger R, Moertl D, Strunk G, Oesterle A, et al. Cost analysis and cost-effectiveness of NT-proBNP-guided heart failure specialist care in addition to home-based nurse care. Eur J Clin Investig. 2011;41(3):315-22. https://doi.org/10.1111/j.1365-2362.2010.02412.x.

71. Turner DA, Paul S, Stone MA, Juarez-Garcia A, Squire I, Khunti K. Costeffectiveness of a disease management programme for secondary prevention of coronary heart disease and heart failure in primary care. Heart. 2008;94(12):1601-6. https://doi.org/10.1136/hrt.2007.125708.

72. Stewart S, Blue L, Walker A, Morrison C, McMurray JJ. An economic analysis of specialist heart failure nurse management in the UK; can we afford not to implement it? Eur Heart J. 2002;23(17):1369-78. https://doi.org/10.1053/ euhj.2001.3114.

73. Postmus D, Pari AA, Jaarsma T, Luttik ML, van Veldhuisen DJ, Hillege $H L$, et al. A trial-based economic evaluation of 2 nurse-led disease management programs in heart failure. Am Heart J. 2011;162(6):1096-104. https://doi. org/10.1016/j.ahj.2011.09.019.

74. Meads DM, O'Dwyer JL, Hulme CT, Lopez RR, Bennett MI. Cost-effectiveness of pain management strategies in advanced Cancer. Int J Technol Assess Health Care. 2019;35(2):141-9. https://doi.org/10.1017/S0266462319000114.

75. Ankuda CK, Meier DE. Predictors of reliably high-value end-of-life care. Curr. 2018;12(4):460-5.

76. Bainbridge DS, H.Sussman, J. Common components of efficacious in-home end-of-life care programs: A review of systematic reviews. J Am Geriatr Soc 2016;64(3):632-639, DOl: https://doi.org/10.1111/jgs.14025.

77. Davies EH, I. J. Systematic review of specialist palliative day-care for adults with cancer. Supportive Care Cancer. 2005;13(8):607-27. https://doi.org/10.1 007/s00520-004-0739-6.

78. Bibas L, Peretz-Larochelle M, Adhikari NK, Goldfarb MJ, Luk A, Englesakis M, et al. Association of Surrogate Decision-making Interventions for critically ill adults with patient, family, and resource use outcomes: A systematic review and meta-analysis. JAMA netw. 2019;2(7):e197229. https://doi.org/10.1001/ja manetworkopen.2019.7229.

79. Datla S, Verberkt CA, Hoye A, Janssen DJA, Johnson MJ. Multi-disciplinary palliative care is effective in people with symptomatic heart failure: A systematic review and narrative synthesis. Palliat Med. 2019;33(8):1003-16. https://doi.org/10.1177/0269216319859148.

80. Molloy D, Guyatt GH, Russo R, et al. Systematic implementation of an advance directive program in nursing homes: A randomized controlled trial. JAMA. 2000;283(11):1437-44. https://doi.org/10.1001/jama.283.11.1437.

81. Teo W-SK, Raj AG, Tan WS, Ng CWL, Heng BH, Leong IY-O. Economic impact analysis of an end-of-life programme for nursing home residents. Palliat Med. 2014;28(5):430-7. https://doi.org/10.1177/0269216314526270.

82. Nicholas LH, Bynum JP, Iwashyna TJ, Weir DR, Langa KM. Advance directives and nursing home stays associated with less aggressive end-of-life care for patients with severe dementia. Health Affairs (Project Hope). 2014;33(4):66774. https://doi.org/10.1377/hlthaff.2013.1258.

83. Gleeson A, Noble S, Mann M. Advance care planning for home health staff: a systematic review. BMJ Support Palliat Care. 2019;26:26.

84. Maltoni M, Caraceni A, Brunelli C, Broeckaert B, Christakis N, Eychmueller S, et al. Prognostic factors in advanced cancer patients: evidence-based clinical recommendations--a study by the steering Committee of the European Association for palliative care. J Clin Oncol. 2005;23(25):6240-8. https://doi. org/10.1200/JCO.2005.06.866

85. Tilburgs B, Vernooij-Dassen M, Koopmans R, van Gennip H, Engels Y, Perry M. Barriers and facilitators for GPs in dementia advance care planning: A systematic integrative review. PLoS One. 2018;13(6):e0198535. https://doi. org/10.1371/journal.pone.0198535.

86. Gardiner C, Ryan T, Gott M. What is the cost of palliative care in the UK? A systematic review. BMJ Support Palliat Care. 2018;8(3):250-7. https://doi. org/10.1136/bmjspcare-2018-001519.

87. Kinghorn P, Coast J. Appropriate frameworks for economic evaluation of end of life care: A qualitative investigation with stakeholders. Palliat Med. 2019;0269216319839635.
88. Huynh E, Coast J, Rose J, Kinghorn P, Flynn T. Values for the ICECAPSupportive Care Measure (ICECAP-SCM) for use in economic evaluation at end of life. Soc Sci Med (1982). 2017;189:114-28.

89. Lorenz KA, Lynn J, Dy SM, Shugarman LR, Wilkinson A, Mularski RA, et al. Evidence for improving palliative Care at the end of life: A systematic ReviewEvidence for improving palliative Care at the end of life. Ann Intern Med. 2008;148(2):147-59. https://doi.org/10.7326/0003-4819-148-2-2008011 50-00010.

90. Ernecoff NC, Stearns SC. Costs at the end of life: perspectives for North Carolina. N C Med J. 2018;79(1):43-5. https://doi.org/10.18043/ncm.79.1.43.

91. Reeve $R$, Srasuebkul P, Langton JM, Haas M, Viney R, Pearson S-A, et al. Health care use and costs at the end of life: a comparison of elderly Australian decedents with and without a cancer history. BMC Palliative Care. 2017;17(1):1-.

92. Davies JM, Gao W, Sleeman KE, Lindsey K, Murtagh FE, Teno JM, et al. Using routine data to improve palliative and end of life care. BMJ Support Palliat Care. 2016;6(3):257-62. https://doi.org/10.1136/bmjspcare-2015-000994.

\section{Publisher's Note}

Springer Nature remains neutral with regard to jurisdictional claims in published maps and institutional affiliations.

\section{Ready to submit your research? Choose BMC and benefit from:}

- fast, convenient online submission

- thorough peer review by experienced researchers in your field

- rapid publication on acceptance

- support for research data, including large and complex data types

- gold Open Access which fosters wider collaboration and increased citations

- maximum visibility for your research: over $100 \mathrm{M}$ website views per year

At $\mathrm{BMC}$, research is always in progress.

Learn more biomedcentral.com/submissions 